\title{
COMPARISON OF DIFFERENT LACTATION CURVE MODELS TO DESCRIBE LACTATION CURVE IN AWASSI SHEEP RAISED IN TURKEY
}

\author{
TEKel, N. ${ }^{1}$ - ŞIRELI, H. D. ${ }^{1}$ - KARATAŞ, A. ${ }^{2}$ - VURAL, M. E. ${ }^{2}$ - KONCAGÜL, S. ${ }^{3}-$ TUtKUN, M. $^{1 *}$ \\ ${ }^{1}$ University of Dicle, Faculty of Agriculture, Department of Animal Science, Diyarbakır, Turkey \\ ${ }^{2}$ GAP International Agricultural Research and Training Center, Diyarbakur, Turkey \\ ${ }^{3}$ Ankara University, Faculty of Agriculture, Department of Animal Science, Ankara, Turkey \\ *Corresponding author \\ e-mail: tutkunmuhittin@yahoo.com; phone: +90-532-668-7313; fax: +90-412-248-5381
}

(Received 23 $3^{\text {rd }}$ Jul 2019; accepted $15^{\text {th }}$ Nov 2019)

\begin{abstract}
The study was carried out in the International GAP Agricultural Research and Training Centre (GATEA) between the years 2010-2014 in Diyarbakır, Turkey. The aims of this study were 1) to compare 8 different models (MG, Dhanoa, Nelder, Wood, CLD, and 2nd-, 3rd- and 4th-degree polynomial) used to describe the lactation curve for Awassi sheep by using 557 completed lactation milk yield records, and 2) to identify the suitable model. In addition, the most effects of birth season, parity, and birth type on the lactation milk yield and parameters on the identified model were investigated. As a result of this study, it was determined that the 4th-degree polynomial (POL4) model is the most suitable. In addition, it was found that all the factors, excluding birth type, have significant effects on the model parameters and lactation milk yield $(\mathrm{P}<0.05)$.
\end{abstract}

Keywords: sheep, milk yield, lactation curve,mathematical model, curve fitting

\section{Introduction}

In Turkey, seventeen percent of the total sheep population is raised in the Southeastern Anatolia Region of Turkey (Anonymous, 2017). The Awassi sheep is the prevalent in the region due to high milk yield. However, the milk yield of Awassi shows wide variation depending on the level of breeding in milk yield, age and weight at birth, lambing month, birth type, production system, and lactation period. Average lactation milk yield of the sheep raised in Southeastern Anatolia is about 80-100 kg/lac (Kaymakç1, 2006), and some breeding studies must be performed in that region in order to benefit from the higher milk yield potential of the Awassi sheep.

In the case of milk production, the appropriate description of the lactation curve is a useful tool in management decision making and in design genetic improvement strategies for the group of animals evaluated (Vázquez-Peláez et al., 2014). A lactation curve is defined as the variation of milk yield depending on time, representing of the milk yield with respect to time using a figure, or the milk yield shown in a figure after lambing (Keskin, 2006; Koncagül et al., 2012). Lactation curves can be beneficial in terms of biological and economic efficiency, selection, monitoring of animal health, ration formulation, and determination of type of care and feeding methods (Wood, 1967; Ruiz et al., 2000; Dağ et al., 2005; Koncagül et al., 2012). Moreover, it is possible to use lactation curve models to estimate the total lactation milk yield from partial lactations and to use the peak yield and persistency values as selection criteria in developing a model for the improvement of milk yield (Wiggans and Gangler, 1999; 
Takma et al., 2009). The shape of the lactation curve and environmental factors that affect the curve can be used to determine the biological affectivity (Grossman and Koops, 1988). The environmental factors that affect the milk yield and lactation curve have been determined by many researchers, and different mathematical models have been proposed for determining the lactation milk yield in dairy cattle (Koncagül and Yazgan, 2011). Most of these models developed for dairy cattle can also be used to identify the lactation curves of sheep and goats (Fernandez et al., 2002; Koncagül et al., 2012; Angeles-Hernandez et al., 2013). Among them, Wood's model (1967) has been the most widely used (Nezamidoust et al., 2013; Angeles-Hernandez et al., 2013)

Lactation curve studies have conducted rarely in Awassi sheep. The aims of this study were to compare 8 different models (MG, Dhanoa, Nelder, Wood, CLD, POL2, POL3, and POL4) used to define the lactation curve for the Awassi breed and to identify the suitable models. In addition, the effects of birth season, parity, and birth types on lactation milk yield and model parameters were investigated.

\section{Material and Methods}

\section{Data}

The experiment was conducted in the International GAP Agricultural Research and Training Centre (GATEA) between the years 2010-2014 in Diyarbakır, Turkey (37 $57^{\prime} 41 \mathrm{~N}$ and $40^{\circ} 13^{\prime} 54 \mathrm{E}, 650 \mathrm{~m}$ asl) (Fig. 1). Study area has a semi-arid climate and is very hot during the summer months. The temperature rises above $40^{\circ} \mathrm{C}$ in summer. Rainfall is almost non-existent during the summer months. Winters are cool and wet. Spring and automn are warm and wet as well.

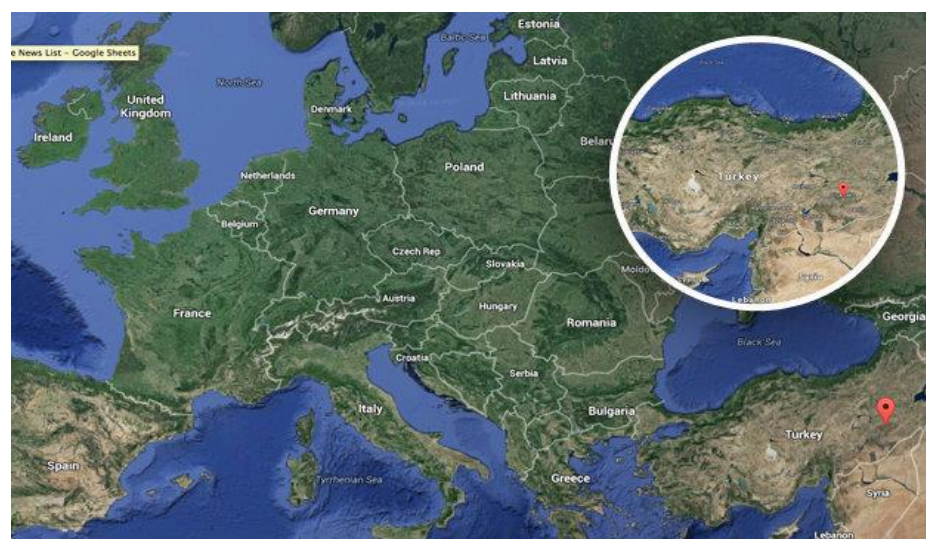

Figure 1. Study location map (https://www.express.co.uk)

The animal material consisted of 557 Awassi sheep raised in training center above mentioned. Semi-intensive care and feeding was applied in addition to 10 hours of pasture time each day, and supplementary feeding was provided following pasture. The milk controls were started 15 days after the first lambing occurred in the herd, and the amount of milk was measured on a scale with $50 \mathrm{~g}$ of precision and repeated every 14 days interval until the end of lactation. The test day of the milking were made at 14 days intervals (Gürsu and Aygün, 2014). Lactation milk yield (LMY) was calculated using the Fleischmann method (Barillet et al., 1992). 


\section{Data Analysis}

The models used in this study were chosen from among the models applied previously to describe lactation curves of sheep. For the analyses of the lactation, the following models were used.

MG model (Morant and Gnanasakthy, 1989):

$$
y_{t}=e^{\left(a-b t_{1}-c t_{1}^{2}-d / t\right)}
$$

Nel model (Nelder, 1966):

$$
y_{t}=t / a+b t+c t^{2}
$$

Wood model (Wood, 1967):

$$
y_{t}=a t^{b} e^{-c t}
$$

CLD model (Cobby and Le Du, 1978):

$$
\mathrm{y}_{\mathrm{t}}=\mathrm{a}-\mathrm{bt}-\mathrm{ae^{-ct }}
$$

Dhanoa model (1981):

$$
y_{t}=a t^{b c} e^{-c t}
$$

Three polynomials: the second degree (POL2):

$$
\mathrm{y}_{\mathrm{t}}=\mathrm{a}+\mathrm{bt}+\mathrm{ct} \mathrm{t}^{2}
$$

The third degree (POL3):

$$
\mathrm{y}_{\mathrm{t}}=\mathrm{a}+\mathrm{bt}+\mathrm{ct}^{2}+\mathrm{dt}^{3}
$$

The fourth degree (POL4):

$$
y_{t}=a+b t+c t^{2}+d t^{3}+e t^{4}
$$

The parameters of the models defined above were as follows: yt is the milk yield on the tth day after lambing; $a, b, c, d$ and e are the model parameters; $t$ is the th day after lambing; and $\mathrm{t} 1=(\mathrm{t}$-lactation period / 2) / 100. Starting values for the parameters of the models mentioned in " $\mathrm{a}, \mathrm{b}, \mathrm{c} \mathrm{d}$ and $\mathrm{e}$ " were taken from various analyses conducted by many researcher such as Dağ et al. (2005).

Analyses were performed using the Proc Nlin procedure in the SAS program (SAS, 2000). For the comparison of the models, the coefficient of determination $\left(R^{2}\right)$, mean square error (RMSE), and correlation coefficient ( $r$ ) between observed and estimated 
lactation curves were considered as the comparison criteria. After identifying the best mathematical model description of the lactation curve, the estimated lactation milk yield (ELMY) for each sheep was calculated using the parameters of the identified model. Then, the ELMY was compared with the LMY calculated by the Fleischmann method (Barillet et al., 1992) described below:

$$
L S V=S_{1} x A_{1}+\sum_{i=2}^{n} \frac{S_{i}+S_{i-1}}{2} A_{i}+S_{n} x 15
$$

where LMY is lactation milk yield, Ai is the number of days between lambing and first milk control day, $A_{1}$ is the number of days between the ith and (i-1)th control milking, $\mathrm{Si}$ is the amount of milk in the ith control milking day, and 15 is the number of days assumed to have passed between the last day of control milking and the end of the lactation. The values of LMY and ELMY were adjusted to 180 days of lactation length.

The correlation coefficients between LMY and ELMY were calculated by the Proc Corr procedure in SAS (2000).

In order to examine the effects of environmental factors on the model parameters, LMY and ELMY, the linear model given below was used in the Proc Glm procedure in SAS (2000):

$$
Y i j k l=\mu+P i+L S j+B T k+e i j k l
$$

where Yijklm is the model parameters, LMY or ELMY, $\mu$ refers to the average value for the trait being analyzed, $\mathrm{Pi}$ is the effect of the ith parity, LSj is the effect of the jth lambing season, BTk is the effect of the kth birth type, and eijkl refers to the random residual. Differences among the means of the environmental factors were tested using the Tukey-Cramer test option.

\section{Results}

\section{Model Selection}

Fit statistics of the mathematical model are given in Table 1. In terms of mean square error (MSE), the highest value was observed in the Dhanoa model, followed by the Wood, CLD, MG, and Nelder models, respectively. It has also been determined that MSEs obtained from polynomial models were not different from zero. The best performance in terms of determination coefficient $\left(\mathrm{R}^{2}\right)$ belonged to the polynomial and Nelder models. POL4 has the highest $\mathrm{R}^{2}$ value (0.99), followed by the POL3, POL2, and Nelder models $\left(0.98,0.97\right.$, and 0.93 , respectively). $\mathrm{R}^{2}$ values of the other models were below 0.85. A similar situation was also observed in terms of the correlation coefficient (r) between observed and estimated lactation curves. POL4 (0.90) had the highest value in terms of correlation coefficient, followed by the POL3, POL2, and CLD models $(0.84,0.74$, and 0.69 , respectively). The correlation coefficients obtained from the other models were found to have lower values.

Considering the MSE, $\mathrm{R}^{2}$, and $\mathrm{r}$ parameters all together, it was concluded that the best model to properly identify the lactation curves of the Awassi sheep breed was POL4. Therefore, the characteristics of lactation curve and environmental factors affecting the LMY were investigated by taking into account the POL4 model. 
Table 1. Comparison criteriaof models used fordescibing lactation curves of Awassi sheep

\begin{tabular}{c|c|c|c}
\hline Model & MSE & $\mathbf{R}^{\mathbf{2}}$ & $\mathbf{r}$ \\
\hline MG & $150 \pm 9.333$ & $0.06 \pm 0.126$ & $0.12 \pm 0.022$ \\
Dhanoa & $532.37 \pm 9.996$ & $0.35 \pm 0.019$ & $0.12 \pm 0.025$ \\
Nelder & $39.68 \pm 5.197$ & $0.93 \pm 0.003$ & $0.51 \pm 0.018$ \\
Wood & $530.52 \pm 9.969$ & $0.35 \pm 0.019$ & $0.13 \pm 0.026$ \\
CLD & $151.76 \pm 6.584$ & $0.84 \pm 0.009$ & $0.69 \pm 0.011$ \\
POL2 & $0.00 \pm 3.192$ & $0.97 \pm 0.001$ & $0.74 \pm 0.009$ \\
POL3 & $0.00 \pm 2.574$ & $0.98 \pm 0.001$ & $0.84 \pm 0.007$ \\
POL4 & $0.00 \pm 1.989$ & $0.99 \pm 0.001$ & $0.90 \pm 0.005$ \\
\hline
\end{tabular}

$\mathrm{R}^{2}$ : coefficient of determination, MSE: Mean square eroor, $\mathrm{r}$ : correlation coefficient between observed and estimated lactaion curve, MG: Morantand Gnanasakthy model, Dhanoa: Dhanoa model, Nelder: Nelder model, Wood: Wood model, CLD: Cobby and Le Du model, POL2: 2nd degree polynomial model, POL3: 3rd degree polynomial model, POL4: 4rd degree polynomial model

\section{Model Parameters}

The model parameters, standard deviations and correlations between model parameters are given in Table 2. Accordingly, parameter (a) refers to the milk yield when standardized time was equal to zero. Standardized time is in the range between -1 and +1 ; when time is at 0 , it has been accepted as the middle of lactation (midpoint). Therefore, parameter (a) represents the estimated milk yield in the middle of lactation. Parameters (b) and (c) refer to the increases and decreases in milk yield until the midpoint of lactation, and parameters (d) and (e) refer to the increases and decreases in milk yield after the midpoint of lactation.

Table 2. Parameters $( \pm S E)$ of POL4 function, LMY means $( \pm S E)(\mathrm{kg})$, and correlation coefficients between model parameters

\begin{tabular}{|c|c|c|c|c|c|c|c|}
\hline Factors & $\mathbf{N}$ & $\mathbf{a}$ & b & c & d & e & LMY \\
\hline \multicolumn{8}{|l|}{ Parity } \\
\hline 1 & 141 & $628 \pm 139.6^{\mathrm{a}}$ & $-470 \pm 168.5$ & $326 \pm 87.4^{\mathrm{a}}$ & $-49 \pm 18.6^{a}$ & $1.0 \pm 1.35^{\mathrm{a}}$ & $109 \pm 5.4^{\mathrm{a}}$ \\
\hline 2 & 132 & $936 \pm 137.0^{\mathrm{ab}}$ & $-554 \pm 165.4$ & $363 \pm 85.8^{\mathrm{a}}$ & $-58 \pm 18.2^{\mathrm{a}}$ & $1.6 \pm 1.32^{\mathrm{a}}$ & $129 \pm 5.3^{b}$ \\
\hline 3 & 103 & $1059 \pm 139.4^{\mathrm{b}}$ & $-218 \pm 168.2$ & $96 \pm 87.2^{\mathrm{b}}$ & $-6 \pm 18.6^{\mathrm{b}}$ & $-3.1 \pm 1.35^{\mathrm{b}}$ & $139 \pm 5.4^{\mathrm{b}}$ \\
\hline 4 & 94 & $1221 \pm 140.2^{b}$ & $-606 \pm 169.2$ & $311 \pm 87.7^{\mathrm{ab}}$ & $-41 \pm 18.7^{\mathrm{ab}}$ & $0.2 \pm 1.35^{\mathrm{ab}}$ & $132 \pm 5.4^{b}$ \\
\hline 5 & 51 & $846 \pm 170.5^{\mathrm{ab}}$ & $-510 \pm 205.8$ & $298 \pm 106.7^{\mathrm{ab}}$ & $-39 \pm 22.7^{\mathrm{ab}}$ & $0.1 \pm 1.65^{\mathrm{ab}}$ & $108 \pm 6.6^{\mathrm{a}}$ \\
\hline $6 \leq$ & 36 & $986 \pm 191.2^{\mathrm{ab}}$ & $-691 \pm 230.8$ & $426 \pm 119.7^{\mathrm{ab}}$ & $-73 \pm 25.5^{\mathrm{a}}$ & $2.9 \pm 1.85^{\mathrm{a}}$ & $105 \pm 7.4^{\mathrm{a}}$ \\
\hline \multicolumn{8}{|l|}{ Lambing Season } \\
\hline December-January & 481 & $916 \pm 125.2$ & $-464 \pm 151.1$ & $265 \pm 78.4$ & $-32 \pm 16.7$ & $-0.3 \pm 1.21$ & $126 \pm 4.9^{\mathrm{a}}$ \\
\hline February-March & 76 & $976 \pm 119.7$ & $-552 \pm 144.4$ & $342 \pm 74.9$ & $-53 \pm 15.9$ & $1.2 \pm 1.16$ & $115 \pm 4.6^{\mathrm{b}}$ \\
\hline \multicolumn{8}{|l|}{ Birth Type } \\
\hline Single & 283 & $923 \pm 106.3$ & $-446 \pm 128.3$ & $271 \pm 66.5$ & $-37 \pm 14.2$ & $0.1 \pm 1.03$ & $120 \pm 4.1$ \\
\hline Twin & 274 & $969 \pm 148.3$ & $-570 \pm 178.9$ & $336 \pm 92.8$ & $-48 \pm 19.7$ & $0.8 \pm 1.43$ & $121 \pm 5.8$ \\
\hline \multicolumn{8}{|l|}{ Correlation } \\
\hline A & & & $-0.732^{* *}$ & $0.414^{* *}$ & $-0.224^{* *}$ & $0.125^{* *}$ & $0.235^{* *}$ \\
\hline B & & & & $-0.895^{* *}$ & $0.751^{* *}$ & $-0.637^{* *}$ & 0.065 \\
\hline $\mathrm{C}$ & & & & & $-0.962^{* *}$ & $0.893^{* *}$ & -0.051 \\
\hline $\mathrm{D}$ & & & & & & $-0.980^{* *}$ & 0.040 \\
\hline $\mathrm{E}$ & & & & & & & -0.035 \\
\hline
\end{tabular}

a, b, c, d, e: model parameters of POL4; LMY: lactation milk yield corrected for lactation length 


\section{Relationship Among Parameters}

The correlation coefficients among model parameters are given in Table 2. As expected from polynomial functions, the correlations between sequential parameters (a$\mathrm{b}, \mathrm{b}-\mathrm{c}, \mathrm{c}-\mathrm{d}$, and d-e) have taken negative and increasing values, whereas the correlations between other parameters (a-c, b-d, and c-e) have taken positive and increasing values, respectively. Because linear interpolation is the basis of determination of LMY using the Fleischmann method, the possibility of errors for estimating milk production between two consecutive control days would increase as the interval between two consecutive milk control days increases. However, there were 14 days between the two milk control days in our study; therefore, LMY was assumed to be estimated closer to the actual amount of milk production.

\section{Effects of Environmental Factors}

The mean and standard errors of LMY and model parameters based on environmental factors are given in Table 3. All factors except birth type had significant effects with varying degrees on the model parameters and LMY. The differences between average values of 1st, 5th and 6th lactations and 2nd, 3rd and 4th lactations have been found significant $(\mathrm{P}<0.05)$. The difference between milk yield of the sheep lambing in the December-January season and the February-March season was found significant $(\mathrm{P}<0.05)$. The type of birth did not have any significant effect on the LMY.

Table 3. Descriptive statistics of LL, LMY, ADMY and LMY180 day

\begin{tabular}{c|c|c|c|c|c|c}
\hline & N & Mean & Std.Err. & Min & Max. & CV\% \\
\hline LL & 1077 & 150.3 & 0.77 & 100.0 & 213.0 & 16.9 \\
LMY & 1077 & 123.9 & 1.23 & 40.9 & 268.8 & 32.6 \\
ADMY & 1077 & 819.7 & 6.60 & 361.7 & 1551.6 & 26.4 \\
LMY180 & 1077 & 147.6 & 1.19 & 65.1 & 279.3 & 26.4 \\
\hline
\end{tabular}

N: Number of observation, Std.Err.: Standard error, Min: minimum, Max: maximum, CV\%: coefficient of variation, LL: Lactation length, LMY: Lactation milk yield, ADMY: Avarege Daily milk yield

In this study, all factors except type of birth had significant effects with varying degrees on the model parameters and LMY (Table 2). The differences between average values of 1st, 5th, and 6th lactations and 2nd, 3rd, and 4th lactations were found statistically significant $(\mathrm{P}<0.05)$. As indicated by Mavrogenis (1996), this situation was to be expected because the milk yield of the Awassi sheep increases in the first 4 parities and has a tendency of decreasing in the following parities. The difference between milk yield of the sheep lambing in December-January season and FebruaryMarch season was found statistically significant $(P<0.05)$. This can be explained by the fact that the pasture conditions in the December-January season are better than those of other seasons, and thus sheep can benefit from pastures more than others lambing in other seasons. These pastures lose their efficiency after April due to the rapid warming of the weather in the area where this study was conducted.

The differences between means of 1st lactation and 3rd and 4th lactations have been found statistically significant $(\mathrm{P}<0.05)$. This shows that the peak yield values of 1 st lactation sheep were lower than the peak yield values of 3rd and 4th lactation sheep in terms of parameter (a). The effect of lambing month on parameter (a) was found insignificant, which shows that the peak yield is not affected by the lambing month. The 
differences between levels of birth types in terms of parameter (a), when the time is equal to zero, were found insignificant.

Descriptive statistics of the research data set in lactation milk yield has shown in Table 3.

The effect of parity on the parameter (a) was insignificant, whereas its effect on parameters $\mathrm{c}, \mathrm{d}$, and $\mathrm{e}$ was found to be statistically significant $(\mathrm{P}<0.05)$. The differences between 1st, 2nd, and 3rd lactations in terms of upward oscillation speed (parameter c) before the peak yield were found statistically significant $(\mathrm{P}<0.05)$. In addition, the differences between 1st, 2nd, and 6th and 3rd lactations in terms of upward and downward oscillation speeds after the peak yield were found statistically significant (P<0.05) (Fig. 2).

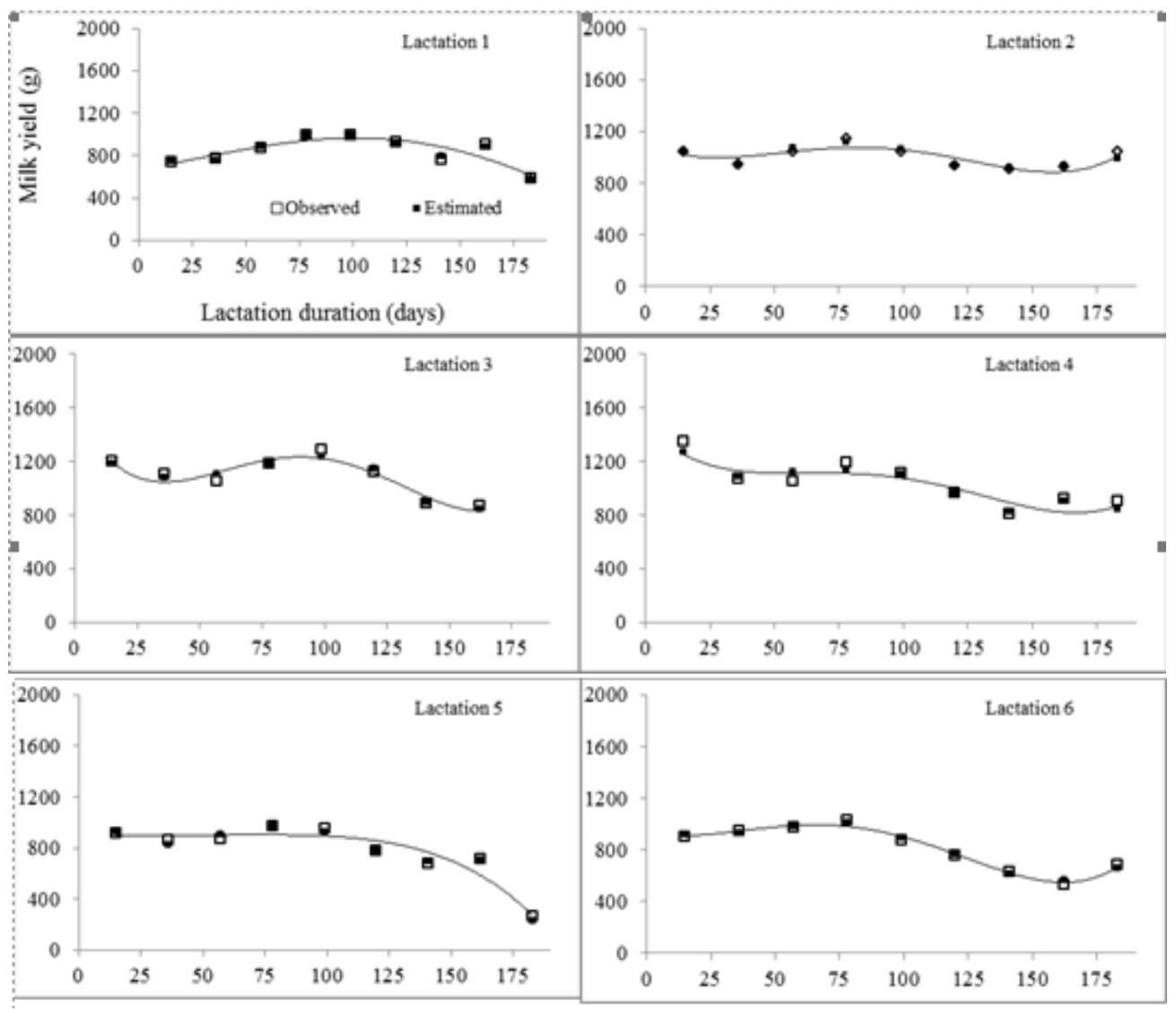

Figure 2. Milk yield vs. lactation duration in different lactation stages

It was found in this study that the best fit model identifying the lactation curve is the POL4 model. Ruiz et al. (2000) reported that in the case of a higher positive correlation between parameters of the mathematical model identifying the lactation curve, the lactation curve model cannot be identified properly. However, in this study, as can be seen in Table 2, because there is a negative correlation between 4th-degree polynomial model parameters in general, this model sufficiently identified the lactation curve of the Awassi sheep breed. Moreover, the highest correlation between LMY and ELMY (0.90) was obtained when the POL4 model was applied, and this indicates that the POL4 model can be used for LMY estimations of the Awassi breed. 


\section{Discussion}

The lactation milk yields found in this research are consistent with the values reported by Dağ et al. (2005), Şeker et al. (2000), and Tekel et al. (2007). In addition, the lactation curve (Fig. 3) shows consistency with the lactation curve given by Kaymakçı (2006). As can be seen in Fig. 3, there was an increase in the first 2 months of lactation, and the peak value was reached; then, a gradual decline was observed. As shown in Fig. 3, the decrease in milk yield accelerates after the first 100th day of lactation approximetly. These changes in ambient temperature and pasture conditions are thought to have an effect on this situation. As a matter of fact, the climatic and pasture conditions in the first 3 months of lactation constitute a suitable environment for milk production of Awassi ewes. However, in the later stages of lactation, the air temperature increases and the pasture conditions decrease significantly due to the temperature increase.

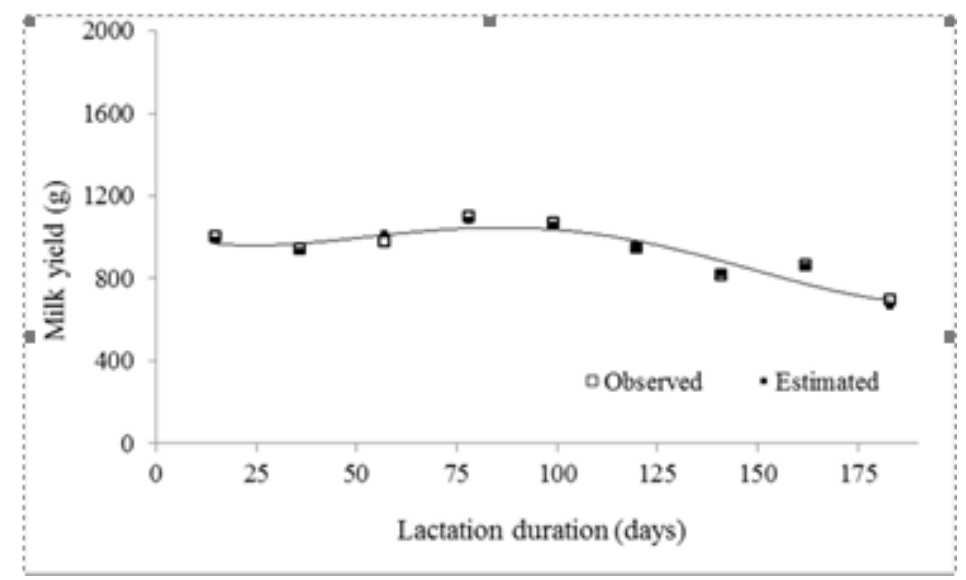

Figure 3. An overall view of the lactation course in Awassi sheep

All of the factors considered in this study, except for the type of birth, had significant effects on model parameters or LMY at various degrees. These results were similar to other studies on the milk yield characteristics of Awassi sheep (Özbey and Akcan, 2000; Reiad et al., 2010; Üstüner and Ogan, 2013). Differences between 1th, 5th, 6th lactations and 2nd, 3rd, 4th lactations were statistically significant $(\mathrm{P}<0.05)$ in terms of LMY. As Mavrogenis (1996) states this sitiuation is expected due to an increase in milk yield in the first 4th lactation and later tendency to decrease in Awassi sheep. The difference between the milk yield of sheep gave birth in December-January and February-March season were statistically significant $(\mathrm{P}<0.05)$. This can be explained by the fact that those who give birth in December-January season have the opportunity to benefit from the pasture for a longer period when the pasture conditions are good. Because the pastures in the region lose their qualities after April due to the rapid heating of the weather.

It has been reported that if there is a high correlation between the parameters of a mathematical model defining the lactation curve, the model used will not define the lactation exactly (Ruiz et al., 2000). When polynomial functions are used in this research, the correlations between sequential parameters (a-b, b-c, c-d, and d-e) have negative and increasing values, whereas the correlations between other parameters (a-c, $\mathrm{b}-\mathrm{d}$, and c-e) have positive and increasing values respectively. Because linear 
interpolation is the basis of determination of LMY using the Fleischmann method, the possibility of errors for estimating milk production between two consecutive control days would increase as the interval between two consecutive milk control days increases. However, the POL4 model showed the best performance in terms of comparison criteria due to high correlation between LMY and ELMY (0.90) was obtained. This indicates that the POL4 model can be used for LMY estimations of the Awassi breed.

Lactation milk yield is determined by genotype and environmental conditions in addition to other quantitative properties. Therefore, the suitability of lactation curve models used by researchers may vary depending on the breed and species. Accordingly, the most appropriate model defining the lactation curve differ from breeds to breeds in different environmental conditions (Ünal et al., 2007). It has been reported that the Pollott Additive and Fractional Polynomial models are the best ones for Lacaune breed (Elvira et al., 2013). In addition, the Wilmink model is the most suitable one, followed by Wood and Dhanoa models, for studies conducted in Akkaraman, KivircikAkkaraman, and Sakız-Akkaraman crossbred sheep (Ünal et al., 2007). It has been determined that Wood, Wilmink, POL2 and POL3 models can be used to estimate milk yield in $\mathrm{F}_{1}$ cross-breeds (Angeles-Hernandez et al., 2013). It has been determined that the Wood model can be used to estimate lactation milk yield in organically raised sheep such as East Friesian, Pelibuey, Suffolk and Black Belly (Angeles-Hernandez et al., 2014). On the other hand, in a study conducted on Awassi sheep, the most suitable model was found to be the Cubic model (Dağ et al., 2005), whereas the Wood model was found to be the best one in another study (Y1ldiz, 1997). Furthermore Wood, Cobby and Le Du, Dhanoa, and Wilmink models have been found equally suitable for studies conducted on the Awassi sheep breed.

\section{Conclusions}

Using of the best suitable lactation model will affect the efficiency and profitability of production. In addition, suitable model provide increasing of the genotypic gain in breeding program. The POL4 model used in the study give better results compared to the other 7 models. The value of ELMY calculated by POL4 was very close to the value of LMY calculated by using the Fleischmann method $(r=0.90)$. This result shows that the POL4 model can be used for LMY estimations of the Awassi sheep breed.

Further researchers are needed to understand different predictive power of models. It is important that different models must be tested by different researchers due to Awassi breed raised in various countries and under different envoirmental conditions.

\section{REFERENCES}

[1] Angeles-Hernandez, J. C., Albarran-Portillo, B., Gomez Gonzalez, A. V., Pescador Salas, N., Gonzalez-Ronquillo, M. (2013): Comparision of Mathemathical models applied to F1 dairy sheep lactations in organic farm and envoirmental factors affecting lactation curve parameter. - Asian Australas. J. Anim. Sci. 26(8): 1119-1126.

[2] Angeles-Hernandez, J. C., Ortega, O. C., Albarran-Portillo, B., Moltaldo, H. H., Gonzalez-Ronquillo, M. (2014): Application of the Wood model to analyse lactation curves of organic dairy sheep farming. - Animal Pruduction Science 54: 1609-1614. 
[3] Anonymous (2017): Livestock Data. - Statistical Institution of Turkey. Available on 10.12.2018 www.tuik.gov.tr. (in Turkish).

[4] Barillet, F., Astruc, J. M., de Brauwer, P., Casu, S., Fabbri, G., Feddersen, E., Frangos, K., Gabina, D., Gama, T. J., Sanna, S. R. (1992): Int. Committee for animal recording guidelines. - International regulations for milk recording in sheep. pp.15, Ins, de Elevage, Paris, France.

[5] Cobby, J. N., Ledu, Y. L. P. (1978): On fitting lactation data. - Anim. Prod. 26: 127-133.

[6] Dăg, B., Keskin, I., Mikailsoy, F. (2005): Application of different model to the lactation curves of unimproved Awassi Ewes in Turkey. - South African Journal of Animal Science 35(4): 238-243.

[7] Dhanoa, M. S. (1981): A note on an alternative form of the lactation model of Wood. Animal Production 32: 349.

[8] Elvira, L., Hernandez, F., Cuesta, P., Cano, S., Gonzalez-Martin, J. V., Astiz, S. (2012): Accurate Mathematical models to describe the lactation curve of Lacune dairy sheep under intensive management. - Animal 7(6): 1044-1052.

[9] Elvira, L., Hernandez, F., Cuesta, P., Cano, S., Gonzalez-Martin, J. V., Astiz, S. (2013): Factors affecting the lactation curves of intensive lymanaged sheep based on a clustering approach. - Journal of Dairy Research 80: 439-447.

[10] Fernandez, C., Sanchez, A., Garces, C. (2002): Modeling the lactation curve for test-day milk yield in Murciano-Granadina goats. - Small Rum Res 46: 29-41.

[11] Grossman, M., Koops, W. J. (1988): Multiphasic analysis of lactation curves in dairy cattle. - J. Dairy Sci 71: 1598-1608.

[12] Gürsu, G., Aygün, T. (2014): Some characteristics of milk yield in Awassi ewes maintained at village conditions. - Journal of Advanced Agricultural Technologies 1:1923.

[13] Kaymakçı, M. (2006): Sheep Breeding. - 2. Press, Meta Pressing, Bornova-İzmir, Turkey. (in Turkish).

[14] Keskin, I., Dağ, B. (2006): Comparison of different mathematical models for describing the complete lactation of Akkaraman ewes in Turkey. - Asian-Aust. J. Anim. Sci. 19: 1551-1555.

[15] Koncagül, S., Yazgan, K. (2011): Comparison of spline and legendre polynomial functions with conventional methods for describing lactation curves of holstein dairy cows. - Hay. Üret. Derg 52(1): 17-23.

[16] Koncagül, S., Daşkıran, İ., Bingöl, M. (2012): Factors affecting lactation milk yield and lactation curve of norduz sheep in farmer condition. - Kafkas Univ. Vet. Fak. Derg. 18(4): 677-684.

[17] Mavrogenis, A. P. (1996): Estimates of environmental and genetic parameters influencing milk and growth traits of Awassi Sheep in Cyprus. - Small Rum. Res. 20: 141-146.

[18] Morant, S. V., Gnanasakthy, A. (1989): A new approach to the mathematical formulation of lactation curves. - Anim. Prod. 49: 151-162.

[19] Nelder, J. A. (1966): Inverse polynomials, a useful group of multi-factor response functions. - Biometrics 22: 128-141.

[20] Nezamidoust, M., Kominakis, A., Safari, A. (2013): Use of Wood's Model to analyse the effects of milking methods on lactation curve in sheep. - Small Rum. Research 113: 195204.

[21] Özbey, O., Akcan, A. (2000): Production performance of Akkaraman, Morkaman and Awasi sheep under semi-intensive conditions I. Fertility and milk production characteristics. - Vet. Bil. Derg. 16(1): 109-120.

[22] Reiad, K., Al-Azzawi, W., Al-Najjar, K., Masri, Y., Salhab, S., Abdo, Z., El-Herek, İ., Omed, H., Saatçı, M. (2010): Factorin fluencing the milk production of Awassi sheep in a flockwiththe ve selectedlines at the Agricultural Scientific Research Center in Salamieh/Syria. - Kafkas Univ. Vet. Fak. Derg. 16(3): 425-430. 
[23] Ruiz, R., Oregui, L. M., Herrerot, M. (2000): Comparison of models for describing the lactation curve of latxa sheep and an analysis of factors affecting milk yield. - Journal of Dairy Science 83(11): 2709-2719.

[24] SAS. (2000): SAS/STAT SAS Inst. Inc. - Cary, NC, USA.

[25] Şeker, İ., Kul, S., Bayraktar, M. (2000): Linear udder traits and relationshiphs between these and milk yield in Awassi and East-Friesian x Awassi crossbreed (F1) ewes. Lalahan Hay. Araşt. Enst. Derg. 40(2): 45-55.

[26] Takma, Ç., Akbaş, Y., Taşkın, T. (2009): Modeling lactation curves of Saanen and Bornova Goats. - Asian Journal of Veterinary Advances 4(3): 122-129.

[27] Tekel, N., Şireli, H. D., Eliçin, M. (2007): A research on the repeatability of milk yield in Awassi sheep. - Harran. Üniversitesi Ziraat Fakültesi Dergisi 11(1/2): 49-53.

[28] Ünal, N., Orman, M. N., Çolak, C., Atasoy, F., Mundan, D., Aytaç, M. (2007): Comparison of various models for lactation curves of Akkaraman sheep and its crossbreed (Chios x Akkaraman F1 and Kıvırcık x Akkaraman F1) ewes. - Lalahan Hay. Arast. Enst. Der. 47(2): 7-13.

[29] Üstüner, H., Ogan, M. M. (2013): Main productive performance of Awassi sheep in the Central Anatolian Region of Turkey. - Turkish Journal of Veterinary and Animal Science 37(3): 271-276.

[30] Vázquez-Peláez, C. G., García-Muñiz, J. G., Lopez-Villalobos, N. (2014): Empirical models used for lactation curve analysis in the Chiapas sheep breed using random regression models. - International Journal of Livestock Production 5(3): 55-64.

[31] Wiggans, G. R., Gangler, N. (1999): Strategies for combing test-day evaluation into on index for lactation performance. - J. Dairy Sci 82: 102.

[32] Wood, P. D. P. (1967): Algebraic model of the lactation curve in cattle. - Nature (tond.) 216: 164-165.

[33] Yildiz, A. (1997): Lactation curve of Awassi sheep and affecting factors in the State of Ceylanpınar Farm. - PhD Thesis, Fırat Üniv. Sağlık Bil. Enst., Elazığ, Turkey. (in Turkish). 